Sri Lankan J. Biol. 2022, 7 (1): 1 - 11

DOI: http://doi.org/10.4038/sljb.v7i1.73

https://orcid.org/0000-0002-3539-2599

Research Article

Open Access

\title{
Biological Fitness Costs Associated with the Various Permethrin Resistance Development Statuses in Anopheles gambiae in Nigeria
}

Ande A.T. ${ }^{1}$, Adelaja O.J. ${ }^{1 *}$, Agada A.V. ${ }^{1}$, Akanni O.I. ${ }^{1}$, Omotayo A.I. ${ }^{1,2}$

${ }^{1}$ Entomological Unit, Department of Zoology, University of Ilorin, Ilorin, Nigeria.

${ }^{2}$ Public Health and Epidemiology Department, Nigeria Institute of Medical Research, Yaba, Lagos.

\begin{abstract}
Man, in a desperate bid to manage malaria-vectors, i.e., Anopheles gambiae s. 1. (Diptera: Culicidae) has relentlessly relied on pyrethroid insecticides especially Permethrin. Unfortunately, these mosquitoes have improved their survival with respect to this approach which must have been associated with some fitness-costs. This study, therefore, evaluates the biological fitness-costs associated with permethrin-resistance development in An. gambiae s.l. in Kwara State, Nigeria. Susceptibility statuses of adult female An. gambiae s.l. populations collected from Oke-odo, Pipeline and Airport were established using World Health Organization test protocol. They were subsequently raised over three-generations and the fecundity, hatchability, development time for larvae, pupae and adult, adult emergence, adult sex ratio was observed, noted, monitored and analysed using ANOVA $(\mathrm{P}<0.05)$. Permethrin-resistant, moderately-resistant and susceptible status were each observed in the An. gambiae s.l. populations of Oke-odo, pipeline and Airport, respectively. The biological fitness-costs showed that permethrin-resistant An. gambiae s.l. had reduced fecundity (First generation $\left(\mathrm{F}_{1}\right)=86.07 \%$, Second generation $\left(\mathrm{F}_{2}\right)=84.55 \%$ and Third generation $\left.\left(\mathrm{F}_{3}\right)=100 \%\right)$ and hatchability $\left(F_{1}=96.58 \%, \quad F_{2}=92.02 \%\right.$ and $\left.F_{3}=100 \%\right)$. Also, there were reduced larvae developmental-time $\left(\mathrm{F}_{1}=35.71 \%\right.$ and $\left.\mathrm{F}_{2}=42.86 \%\right)$, adult-emergence $\left(\mathrm{F}_{1}=97.69 \%\right)$ and longevity $\left(\mathrm{F}_{1}=46.39 \%\right)$ when compared with the susceptible population. Permethrin-resistance development in An. gambiae s.l. definitely comes with some biological fitness-costs that disadvantage its transmission potential and can be leveraged upon in vector-management.
\end{abstract}

Received: 15 March 2021

Accepted: 20 August 2021

\section{Key words:}

Life-history

Management

Susceptible

Vector

*Corresponding author: kayadelaja@gmail.com

\section{Introduction}

Insects remain the most challenging human competitor for his valuable resources and man has relentlessly attempted to abate their actions by unguarded use of insecticides. Insects' competitive status keeps improving, despite the upscale use of insecticides, as a result of the development of salient but effective insecticide resistance survival strategies, wherein resistant alleles that confer generational protection are developed (Sanil \& Shetty, 2012; Brown et al., 2013). This milestone development by insects must have been achieved alongside some physiological fitness cost.
Fitness, i.e., capacity of a population to survive and reproduce, despite the presence of an inimical situation, other species could not stand (Tabbabi \& Ben Cheikh, 2017), entails the deployment of a substantial part of available energy resource to coping with the identified challenge. A fit individual, therefore, suffers an energy resource deficit for other activities and becomes weaker in those respects. Fitness is, therefore, expected to be associated with some costs or weaknesses, that 0 may present in

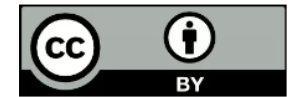

This is an open-access article distributed under the terms of the Creative Commons Attribution 4.0 International License, which permits unrestricted use, distribution and reproduction in any medium provided the original author and source are credited 
various forms in different insects (Jaramillo et al., 2014).

Anopheles gambiae s.l., a renowned mosquito vector of malaria, has been bombarded heavily with pyrethroid insecticides in Nigeria and Africa over the years (WHO, 2016). Pyrethroids, especially Permethrin, has been a major insecticide in use for landmark interventions such as in agricultural, indoor residual spraying (IRS) and Long-lasting Insecticide Treated Nets (LLINs) interventions. Unfortunately, as expected, permethrin resistance was reported as early as 2007 in An. gambiae s.l. (Awolola et al., 2007) and subsequently by Balarabe et al. (2015), Okorie et al. (2015), Habibu et al. (2017), Nwankwo et al. (2017), Awolola et al. (2018) and Oduola et al. (2019) in Nigeria. This trend forced a slight shift of emphasis to the use of Deltamethrin, another pyrethroid, while the malaria burden caused by An. gambiae s.l.in Nigeria and Africa remains staggering (WHO, 2019) owing to pyrethroid resistance. The fitness costs of this notable problematic stance in An. gambiae s.l.is not clearly understood, hence the full implications of the persistence of permethrin resistance on Anopheles species and malaria management remains uncertain.

Okoye et al. (2007) and Lyons et al. (2016) observed that no fitness costs whatsoever was associated with insecticide resistance development in Anopheles funestus. Tabbabi \& Daaboub (2018), however, reported hatchability, fecundity, adult emergence and developmental time fitness costs in Deltamethrin resistant Anopheles labranchiae, while Rahim et al. (2017) reported life history fitness cost in Temephos resistant Aedes albopictus and Thiago et al. (2012) reported the same on Aedes aegypti. Olorunfemi et al. (2016) reported the effect of sublethal doses of Cypermethrin on the life history of Culex quinquefasciatus. Rivero et al. (2011) reported depleted energetic resources of larvae and adult as fitness cost in insecticide-resistant Culex pipiens. The exact imports of the popular An. gambiae s.l. permethrin resistance development in terms of fitness costs is yet to be expressed explicitly. This study, therefore, evaluates biological fitness costs associated with permethrin insecticide resistance development in An. gambiae s.l. populations in Kwara State, Nigeria at each of the three different statuses of permethrin resistance, i.e. susceptible, suspected resistant and resistant, to provide a clear understanding and full implications of the development on the mosquito species and malaria management.

\section{Materials and Methods}

\subsection{Study Area}

Kwara state is in North-Central geopolitical zone of Nigeria, located between latitude $8^{\circ} 30^{\prime} \mathrm{N}$ to $8^{\circ} 47^{\prime} \mathrm{N}$ and longitude $4^{\circ} 20^{\prime} \mathrm{E}$ to $4^{\circ} 52^{\prime} \mathrm{E}$ of the equator. The state experiences two distinct seasons, the wet season that lasts from March to September and the dry season between October and February (The World Gazetteer, 2007). Anopheles gambiae s.l. mosquito populations were sourced from three Local Government Areas (LGAs) i.e. Asa, Ilorin South and Ilorin West of the State. The communities where the Anopheles mosquitoes were sourced from Airport ( $8^{\circ} 26^{\prime}$ $\left.15.59^{\prime \prime} \mathrm{N} ; 4^{\circ} 29^{\prime} 23.99 " \mathrm{~g}\right)$ found in Asa LGA, Oke-odo $\left(8^{\circ} 27^{\prime} 25.2^{\prime \prime N} ; 4^{\circ} 37^{\prime} 47.92^{\prime \prime} \mathrm{E}\right)$ found in Ilorin South LGA and Pipeline ( $8^{\circ} 27^{\prime} 38.28^{\prime \prime} \mathrm{N} ; 4^{\circ} 34^{\prime}$ 43.84" E) found in Ilorin West LGA (Fig. 1).

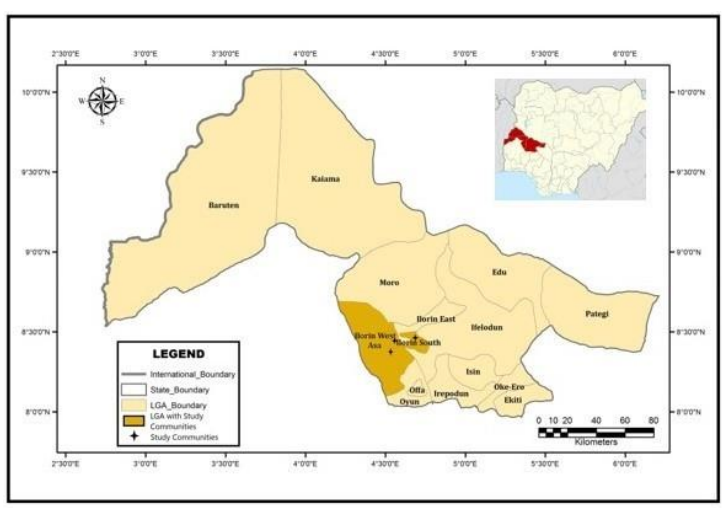

Fig. 1. Map of Nigeria showing Kwara State LGAs and the three communities sampled.

\subsection{Mosquito Collection and Morphological Identification}

An. gambiae s. 1. larvae were recovered from natural breeding sites such as puddles, earthen fish pond surroundings, tire tracks, marshes and puddles in the vicinity of the three sampled locations. The larvae were collected using dippers. Collections from each location were pooled and raised separately. The Anopheles larvae were recognized by their horizontal orientation on the water surface and morphological characters using keys by Gillies \& Coetzee, 1987, sorted out and transported to the Entomology Laboratory, University of Ilorin, Ilorin, Nigeria. The larvae were raised in water media of their natural breeding sites, put to a depth of approximately $2 \mathrm{~cm}$ in plastic trays $(5 \mathrm{~cm} \times 27 \mathrm{~cm} \times 36 \mathrm{~cm})$. Each labelled tray and its larval content were protected with a net and raised in the insectary at an ambient temperature of $25^{\circ} \mathrm{C}$ to $28^{\circ} \mathrm{C}$ and $76 \pm 5 \%$ relative humidity. The larvae were fed on $200 \mathrm{mg}$ mixture of grounded biscuits and yeast powder (ratio 1 to 3 ) twice daily. The larvae development was observed and the resulting pupae were moved into holding cages for adult emergence. Emerged adult mosquitoes were fed mass of cotton wool soaked with $10 \%$ sugar solution.

Some randomly selected adult mosquitoes from each site were immobilised and examined using a dissecting microscope (Olympus SZ 40) for detailed observations and identification of the mosquitoes with particular reference to the head, thorax, wings and 
hind-legs using morphological keys by Gillies \& Coetzee (1987) and they were identified to a species level as An. gambiae s.l.

\subsection{Insecticide Susceptibility Bioassay}

The WHO (2016) standard procedure and susceptibility test kit were used. The assay was conducted on 2-3-day old glucose-fed adult female $A n$. gambiae s.l. which were starved a day before the test. Filter papers impregnated with insecticides $(0.75 \%$ Permethrin) and test kits developed by the World Health Organization were used for the test. The impregnated papers were rolled into holding tubes and fastened with steel-spring wire clips. Five replicates of 25 active female mosquitoes were tested per tube and control. Knockdowns were recorded for 1-hour period in each holding tube and percentage knocked down after $1 \mathrm{hr}$ of exposure was calculated per population as:

$$
\begin{aligned}
& \text { Percentage knockdown }(\%) \\
& =\frac{\text { Total no of knockdown mosquitoes after } 60 \text { minutes }(1 \mathrm{hr})}{\text { Total number of exposed mosquitoes }} \\
& \times 100
\end{aligned}
$$

The exposed and knocked down mosquitoes were subsequently transferred into the holding tube and maintained for 24 hours where sugar solution was made available after which the number of dead mosquitoes was noted and transformed to mortality percentage ratings using the formula:

$$
\begin{aligned}
& \text { Percentage mortality (\%) } \\
& =\frac{\text { Total number of dead mosquitos after } 24 \mathrm{hrs}}{\text { Total number of exposed mosquitoes }} \times 100
\end{aligned}
$$

Correction with Abbott's formula was not necessary, as control mortalities were less than 5\% throughout the test (WHO, 2016).

Overall Resistance status for each of the populations of An. gambiae s.l. was subsequently determined following WHO guidelines, where average mortality rates of between $98 \%$ and $100 \%$ indicate susceptible status, $80 \%$ and $97 \%$ indicates possible resistance that needs to be confirmed and less than $80 \%$ indicates the resistant status (WHO, 2019).

\subsection{Life table study across generations}

After ascertaining the resistance status of each $A n$. gambiae s.l. population from Oke-odo, Pipeline and Airport, all subsequently emerged adults were pooled in a cage per population. Three replicates of twenty (20) sexed individuals comprising of 10 males and 10 females each were sourced from each pool, kept in a labelled cage to identifying the population and replicate number. Each of the cages containing the sexed adults was subsequently treated simultaneously as follows; the adults were offered a sugar solution diet as described earlier and allowed to mate for 2-3 days. The females were blood-fed with human blood for 4 days between 8pm-10 pm daily after which each female was moved into oviposition chambers. After oviposition, all eggs laid were counted with the aid of a hand lens and transferred into larval rearing trays $(5 \mathrm{~cm} \times 27 \mathrm{~cm} \times 36 \mathrm{~cm})$. Hatching was monitored within the tray for timing and numbers per tray, after which, durations of larvae, pupae and adult stages were monitored. The number of adult male and female mosquitoes after emergence were also observed. A concerted attempt was made to raise each of the three populations over three generations. Data were gathered and processed per replicate as follows:

$$
\begin{gathered}
\text { Fecundity rate }\left(\frac{\text { eggs }}{\text { female }}\right)=\frac{\text { Total number of eggs laid }}{10} \\
\text { Hatchability rate }=\frac{\text { Total number of emerged larvae }}{\text { Total number of eggs laid }}
\end{gathered}
$$

$$
\begin{aligned}
& \text { Adult Emergence rate } \\
& =\frac{\text { Number of adult mosquitoes that emerged from the pupae }}{\text { Total number of pupae }}
\end{aligned}
$$

Longevity $=$ Numbers of days lived by the larvae, pupae and adult mosquitoes (days).

Sex ratio $=$ The number of adult male and female mosquitoes that emerged.

\subsection{Data Analysis}

Knock down times for $50 \%$ of the mosquitoes $\left(\mathrm{KDT}_{50}\right)$ were estimated using a log time Probit model with GraphPad prism 8. Data obtained on each parameter were developed into a life table (Olayemi \& Ande, 2009), analysed and were compared per population. Fecundity, Hatchability, Emergence duration, Emergence rate, Larvae, pupae and adult Longevity were calculated using Microsoft Office Excel 2016. The populations were compared to confirm statistical difference using Analysis of Variance (ANOVA) at $95 \%$ confidence level at $\mathrm{P}=0.05$ with the aid of GraphPad prism 8. The values obtained for each population were compared with reference control which is $100 \%$ susceptible and reflected in terms of cost. The following formula was used to evaluate this:

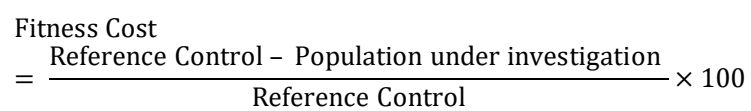

\section{Results}

\subsection{Insecticide Susceptibility Assay}

Figure 2 shows the mean knockdown of An. gambiae s.1. adult mosquito samples from three different communities in Ilorin, Kwara state. An. gambiae s.l. test population from Oke-odo, Pipeline, and Airport had mean knockdown of 13.67 $\pm 4.93,12.33 \pm 3.8$ and $10.00 \pm 4.00$ after 60 minutes of exposure, respectively. There was a significant difference $(\mathrm{P}<0.05)$ at 45 mins 
between the populations from Oke-odo and Airport and also between Oke-odo and Pipeline. There was also a significant difference $(\mathrm{P}>0.05)$ at $60 \mathrm{mins}$ between Oke-odo and Pipeline, Oke-odo and Airport and Pipeline and Airport (Fig. 2).

Table 1 shows the knockdown, mortality and permethrin resistance statuses of An. gambiae s.l. adult mosquito samples from three different communities in Ilorin, Kwara state. The time taken for $50 \%$ of $A n$. gambiae s.l. adult mosquitoes to be totally knocked down was 74.54 mins (61.07 to 90.99), $87.01 \mathrm{mins}$ (64.48 to 117.4 ) and 97.50 mins (70.32 to 135.2$)$, respectively for Permethrin in Oke-odo, Pipeline and Airport populations, respectively (Table 1). After $24 \mathrm{hrs}$ of exposure, mortalities of the mosquito populations were $10 \%$ (6), 56.6\% (34) and 98.3\% (59) and the status of the mosquitoes was adjudged Resistant, Moderately Resistant and Susceptible, respectively for the Oke-odo, Pipeline and Airport populations, respectively based on their mortality rates (Table 1).

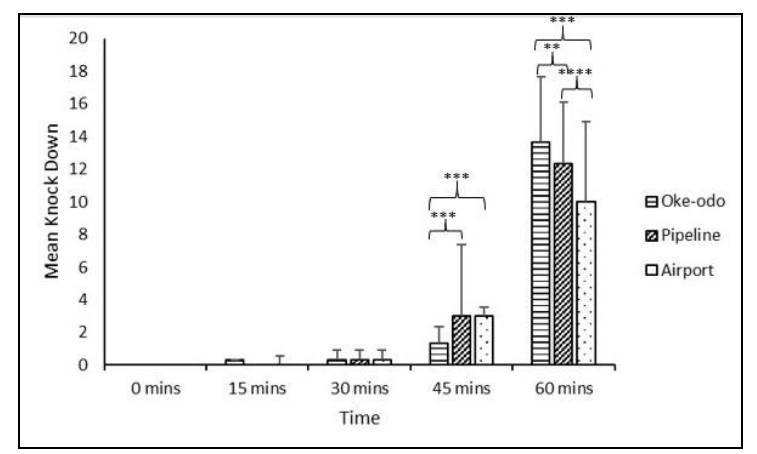

Fig. 2. Progressive means to knockdown An. gambiae s.l. exposed to Permethrin papers.

Table 1. Knockdown, mortality and permethrin resistance statuses of An. gambiae s.l. adult mosquito samples from three different communities in Ilorin, Kwara state.

\begin{tabular}{cccccccc}
\hline Populations & $\begin{array}{c}\text { Number } \\
\text { exposed }\end{array}$ & $\begin{array}{c}\text { Number } \\
\text { KD after } \\
1 \mathrm{hr}\end{array}$ & $\begin{array}{c}\text { \% KD } \\
\text { after } 1 \mathrm{hr}\end{array}$ & $\begin{array}{c}\text { KDT } \\
(95 \% \mathrm{CL})\end{array}$ & $\begin{array}{c}\text { Total } \\
\text { Mortality } \\
\text { after 24hrs }\end{array}$ & $\begin{array}{c}\text { Total } \\
\text { mortality\% }\end{array}$ & $\begin{array}{c}\text { Resistance } \\
\text { Status }\end{array}$ \\
\hline OKE-ODO & 100 & 70 & 70.0 & $\begin{array}{c}74.54 \\
(61.07 \text { to } 90.99)\end{array}$ & 6 & 10.0 & Resistant \\
PIPELINE & 100 & 61.7 & 61.7 & $\begin{array}{c}87.01 \\
(64.48 \text { to } 117.4)\end{array}$ & 34 & 56.6 & $\begin{array}{c}\text { Moderately } \\
\text { Resistant }\end{array}$ \\
AIRPORT & 100 & 50 & 50.0 & $\begin{array}{c}97.50 \\
(70.32 \text { to } 135.2)\end{array}$ & 59 & 98.3 & Susceptible
\end{tabular}

$\mathrm{KD}=$ Knockdown, KDT $=$ Knockdown Time, $\%=$ percentage, $\mathrm{CL}=$ Confidence Limit

\subsection{Larvae Survival Rate}

Figure 3 shows the larvae survival curve for Susceptible, Moderately Resistance and Resistance population of An. gambiae s.l. across three generations. The Airport population displayed higher larval survival rate compared to the Oke-odo and Pipeline population in the first generation. Also, in the same generation, the Oke-ode population displayed a higher larval survival rate when compared with the Pipeline population (Fig. 3a). The Oke-odo population displayed higher larval survival rate compared to the Airport and Pipeline population in the second generation. Also, in the same generation, the Airport population displayed a higher larval survival rate when compared with the Pipeline population (Fig. 3b). In the third generation, the larval survival rate of the Oke-odo population was 100 percent throughout larval duration while the
Airport population displayed a higher larval survival (Fig. 3c).

\subsection{Fecundity}

Table 2 shows the fecundity rates of An. gambiae s.l. adult mosquito samples from three different populations with varying permethrin resistant status from Ilorin, Kwara state. The fecundity rate of each population showed that those from Airport which are the susceptible population laid $122.00 \pm 13.89$ mean number of eggs in the first generation $\left(\mathrm{F}_{1}\right)$, but this reduced to $82.00 \pm 18.52$, and $59.67 \pm 3.21$ in the second $\left(\mathrm{F}_{2}\right)$ and third $\left(\mathrm{F}_{3}\right)$ generations respectively. These respective rates were significantly higher $(\mathrm{P}<$ $0.05)$ than the those laid by the moderately resistant mosquitoes from Pipeline $\left(\mathrm{F}_{1}=40.33 \pm 5.86, \mathrm{~F}_{2}=\right.$ $23.10 \pm 24.38$ and $\left.F_{3}=32.00 \pm 3.00\right)$ and the resistant population from Oke-odo $\left(\mathrm{F}_{1}=17.00 \pm 3.00, \mathrm{~F}_{2}=\right.$ $12.67 \pm 1.53$ and $F_{3}=0.00 \pm 0.00$ ). 


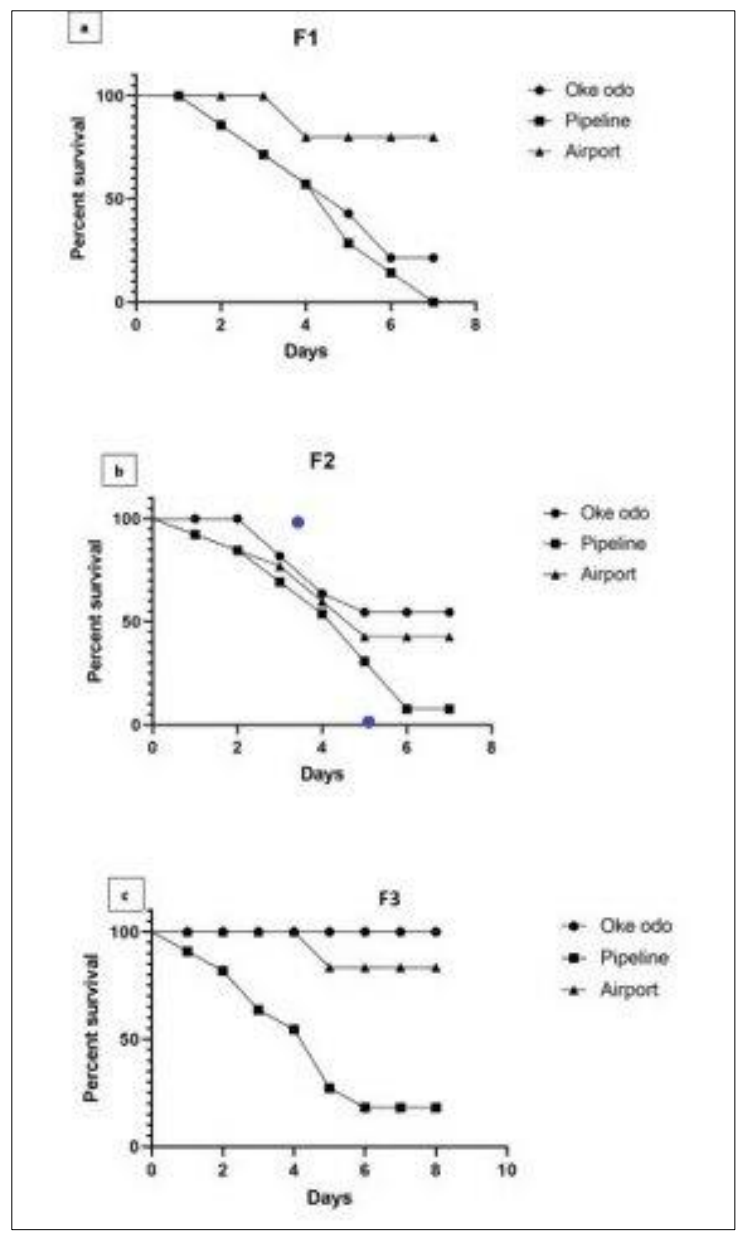

Fig. 3. Larvae survival curve for Susceptible, Moderately Resistance and Resistance population of An. gambiae s.l. across 3 generations.

The resistant population laid fewer eggs at the second generation and did not survive to lay eggs at the third generation, while in the moderately resistant, more eggs were laid in the third generation compared to the second generation (Table 2). There was an $86.07 \%$ fecundity rate reduction or cost due to full resistance development in the resistant Oke Odo population of An. gambiae s.l. in the first generation, and $84.55 \%$ and $100 \%$ costs in the second and third generations, respectively, when compared to the susceptible population from the Airport community. Also, it costed the moderately resistant population of An. gambiae s.l. from Pipeline $66.94 \%$, and $71.83 \%$ and $46.37 \%$ of its ability to lay eggs in the F1, F2 and F3 generations, respectively when compared with the susceptible population from Airport community (Table 2).

\subsection{Hatchability}

The hatchability rates of each population over three generations are as shown in Table 2. Susceptible $A n$. gambiae s.l. populations from Airport hatched a mean of $117.00 \pm 12.12$ eggs in the first generation, and means of $79.33 \pm 17.56$ and $54.67 \pm 3.21$ hatched in F2 and F3 generations, respectively. These were significantly higher $(\mathrm{P}<0.05)$ than the population from Pipeline; moderately resistant population $\left(\mathrm{F}_{1}=\right.$ $\left.39.00 \pm 8.72, \mathrm{~F}_{2}=52.00 \pm 5.00 \mathrm{~F}_{3}=24.67 \pm 7.77\right)$ and the population from Oke-odo; Resistant population $\left(\mathrm{F}_{1}=\right.$ $4.00 \pm 1.00, F_{2}=6.33 \pm 0.58, F_{3}=0.00 \pm 0.00$ ) (Table 2). There was $96.58 \%$ hatchability rate reduction or cost due to Permethrin resistance development in $A n$. gambiae s.l. population in F1, while in F2 and F3 generations a cost of $92.02 \%$ and $100.00 \%$ were recorded. Meanwhile, the cost in the moderately resistant Pipeline population was $66.67 \%$, 34.45\% and $54.87 \%$ in F1, F2 and F3, respectively. (Table 2).

\subsection{Developmental stages longevity}

Table 3 shows the developmental stages longevity of An. gambiae s.l. mosquito at various population with varying permethrin resistance status. The mean larval developmental longevity in the resistant Okeodo population over the two generations of survival were $6.33 \pm 0.58$ days, $6.67 \pm 0.58$ days, respectively. This developmental duration was significantly higher $(\mathrm{P}<0.05)$ than those of the moderately resistant Pipeline population $\left(\mathrm{F}_{1}=4.67 \pm 0.58, \mathrm{~F}_{2}=\right.$ $5.67 \pm 0.58$ and $\mathrm{F}_{3}=7.67 \pm 0.58$ days $)$ and the susceptible Airport population $\left(\mathrm{F}_{1}=4.67 \pm 0.58, \mathrm{~F}_{2}=\right.$ $4.67 \pm 0.58$ and $F_{3}=5.00 \pm 0.58$ days). The resistant population had a longer developmental duration which increased in the second generation. This same trend was noticed in the moderate resistance population where there was an increase in developmental duration at each generation.

There was a $35.71 \%$ increase in the developmental duration or cost due to full resistance development in the resistant Oke-odo population of An. gambiae s.l. in the first generation, and $42.86 \%$ cost in larval development duration in the second generation when compared to the susceptible Airport population. Also, it costed the moderately resistant Pipeline population of An. gambiae s.1. $21.43 \%$ and $35.29 \%$ of its larval developmental duration in the second and third generations, respectively when compared to the susceptible Airport population (Table 3). The mean pupae developmental longevity in the resistant Oke-odo population in the first generations of survival was $2.33 \pm 0.58$ days. This developmental duration was the same as those of the moderately resistant Pipeline population and the susceptible Airport population $(2.33 \pm 0.58$ days $)$ The developmental duration in the second generation was the same in the moderately resistant population and susceptible population $(1.67 \pm 0.58$ days $)$ which was less than what was observed in the first generation. Meanwhile, in the third generation the developmental duration in the pupae of the moderately resistant population $(1.67 \pm 0.58$ days $)$ was significantly higher $(\mathrm{P}<0.05)$ when compared with the susceptible population $(1.33 \pm 0.58$ days). 
Table 2. Fecundity and Hatchability rates of An. gambiae s.l. adult mosquito samples from three different populations in Ilorin, Kwara state. Mean Fecundity Rate Mean Hatchability Rate

Populations

Mean Hatchability Rate

\begin{tabular}{|c|c|c|c|c|c|c|c|c|}
\hline & & & & \multirow{2}{*}{$(\% \mathrm{FC})$} & & \multirow{2}{*}{$(\% \mathrm{FC})$} \\
\hline & $\begin{array}{c}\text { Mean } \pm \text { SD } \\
(\% \mathrm{FC})\end{array}$ & $\begin{array}{c}\text { Mean } \pm \text { SD } \\
(\% \mathrm{FC})\end{array}$ & $\begin{array}{c}\text { Mean } \pm \text { SD } \\
(\% \text { FC) }\end{array}$ & & Mean \pm SD $(\%$ FC $)$ & $\begin{array}{c}\text { Mean } \pm \text { SD } \\
(\% \mathrm{FC})\end{array}$ & $\begin{array}{c}\text { Mean } \pm \text { SD } \\
(\% \mathrm{FC})\end{array}$ & \\
\hline Resistant & $\begin{array}{c}17.00 \pm 3.00^{\mathrm{a}} \\
(86.07)\end{array}$ & $\begin{array}{c}12.67 \pm 1.53^{\mathrm{a}} \\
(84.55)\end{array}$ & $\begin{array}{c}0.00 \pm 0.00^{\mathrm{a}} \\
(100)\end{array}$ & $\begin{array}{c}9.89 \pm 8.83^{\mathrm{a}} \\
(90.21)\end{array}$ & $\begin{array}{c}4.00 \pm 1.00^{\mathrm{a}} \\
(96.58)\end{array}$ & $\begin{array}{c}6.33 \pm 0.58^{\mathrm{a}} \\
(92.02)\end{array}$ & $\begin{array}{c}0.00 \pm 0.00^{\mathrm{a}} \\
(100)\end{array}$ & $\begin{array}{c}3.44 \pm 3.20^{\mathrm{a}} \\
(96.20)\end{array}$ \\
\hline $\begin{array}{l}\text { Moderately } \\
\text { Resistant }\end{array}$ & $\begin{array}{c}40.33 \pm 5.86^{\mathrm{b}} \\
(66.94)\end{array}$ & $\begin{array}{c}23.10 \pm 24.38^{\mathrm{b}} \\
(71.83)\end{array}$ & $\begin{array}{c}32.00 \pm 3.00^{\mathrm{b}} \\
(46.37)\end{array}$ & $\begin{array}{c}31.81 \pm 8.62^{b} \\
(61.71)\end{array}$ & $\begin{array}{c}39.00 \pm 8.72^{\mathrm{b}} \\
(66.67)\end{array}$ & $\begin{array}{c}52.00 \pm 5.00^{\mathrm{b}} \\
(34.45)\end{array}$ & $\begin{array}{c}24.67 \pm 7.77^{\mathrm{b}} \\
(54.87)\end{array}$ & $\begin{array}{c}38.56 \pm 13.67 \\
(52.00)\end{array}$ \\
\hline Susceptible & $\begin{array}{c}122.00 \pm 13.89^{\mathrm{c}} \\
(0)\end{array}$ & $\begin{array}{c}82.00 \pm 18.52^{\mathrm{c}} \\
(0)\end{array}$ & $\begin{array}{c}59.67 \pm 3.21^{\mathrm{c}} \\
(0)\end{array}$ & $\begin{array}{c}87.89 \pm 31.58^{\mathrm{c}} \\
(0)\end{array}$ & $117.00 \pm 12.12^{\mathrm{c}}(0)$ & $\begin{array}{c}79.33 \pm 17.56^{\mathrm{c}} \\
(0)\end{array}$ & $\begin{array}{c}54.67 \pm 3.21^{\mathrm{c}} \\
(0)\end{array}$ & $\begin{array}{c}83.67 \pm 31.39 \\
(0)\end{array}$ \\
\hline
\end{tabular}

Mean values having the same letter superscript along the same column are not significantly different ( $\mathrm{P}=0.05$; Tukey's HSD Test), \% FC = Fitness Cost.

Table 3. The developmental stage longevity of An. gambiae s.l. from three different populations in Ilorin, Kwara state.

\begin{tabular}{|c|c|c|c|c|c|c|c|c|c|c|c|c|}
\hline \multirow[t]{3}{*}{ Populations } & \multicolumn{4}{|c|}{ Larvae Longevity (days) } & \multicolumn{4}{|c|}{ Pupae Longevity (days) } & \multicolumn{4}{|c|}{ Adult Longevity (days) } \\
\hline & $\mathrm{F}_{1}$ & $\mathrm{~F}_{2}$ & $\mathrm{~F}_{3}$ & Avg. $(\% \mathrm{FC})$ & $\mathrm{F}_{1}$ & $\mathrm{~F}_{2}$ & $\mathrm{~F}_{3}$ & Avg. (\%FC) & $\mathrm{F}_{1}$ & $\mathrm{~F}_{2}$ & $\mathrm{~F}_{3}$ & Avg. (\%FC) \\
\hline & $\begin{array}{c}\text { Mean } \pm \text { SD } \\
(\% \mathrm{FC})\end{array}$ & $\begin{array}{c}\text { Mean } \pm \text { SD } \\
(\% \mathrm{FC})\end{array}$ & $\begin{array}{c}\text { Mean } \pm \text { SD } \\
(\% \mathrm{FC})\end{array}$ & & $\begin{array}{c}\text { Mean } \pm \text { SD } \\
(\% \mathrm{FC})\end{array}$ & $\begin{array}{c}\text { Mean } \pm \text { SD } \\
(\% \mathrm{FC})\end{array}$ & $\begin{array}{c}\text { Mean } \pm \text { SD } \\
(\% \mathrm{FC})\end{array}$ & & $\begin{array}{c}\text { Mean } \pm \text { SD } \\
(\% \mathrm{FC})\end{array}$ & $\begin{array}{c}\text { Mean } \pm \text { SD } \\
(\% \mathrm{FC})\end{array}$ & $\begin{array}{c}\text { Mean } \pm \text { SD } \\
(\% \mathrm{FC})\end{array}$ & \\
\hline Resistant & $\begin{array}{c}6.33 \pm 0.58^{\mathrm{a}} \\
(-35.71)\end{array}$ & $\begin{array}{c}6.67 \pm 0.58^{\mathrm{a}} \\
(-42.86)\end{array}$ & $\begin{array}{l}0.00 \pm 0.00^{\mathrm{a}} \\
(-100)\end{array}$ & $\begin{array}{c}4.33 \pm 3.76^{\mathrm{a}} \\
(-59.52)\end{array}$ & $\begin{array}{c}2.33 \pm 0.58^{\mathrm{a}} \\
(0)\end{array}$ & $\begin{array}{l}0.00 \pm 0.00^{\mathrm{a}} \\
(-100)\end{array}$ & $\begin{array}{l}0.00 \pm 0.00^{\mathrm{a}} \\
(-100)\end{array}$ & $\begin{array}{c}0.78 \pm 1.35^{\mathrm{a}} \\
(-66.67)\end{array}$ & $\begin{array}{c}10.67 \pm 2.52^{a} \\
(-46.39)\end{array}$ & $\begin{array}{c}0.00 \pm 0.00^{\mathrm{a}} \\
(-100)\end{array}$ & $\begin{array}{c}0.00 \pm 0.00^{\mathrm{a}} \\
(-100)\end{array}$ & $\begin{array}{c}3.56 \pm 0.84^{\mathrm{a}} \\
(-82.13)\end{array}$ \\
\hline $\begin{array}{c}\text { Moderately } \\
\text { Resistant }\end{array}$ & $\begin{array}{c}4.67 \pm 0.58^{\mathrm{b}} \\
(0)\end{array}$ & $\begin{array}{c}5.67 \pm 0.58^{\mathrm{b}} \\
(-21.43)\end{array}$ & $\begin{array}{c}7.67 \pm 0.58^{\mathrm{b}} \\
(-35.29)\end{array}$ & $\begin{array}{c}6.00 \pm 1.53^{b} \\
(-18.91)\end{array}$ & $\begin{array}{c}2.33 \pm 0.58^{\mathrm{a}} \\
(0)\end{array}$ & $\begin{array}{c}1.67 \pm 0.58^{\mathrm{b}} \\
(0)\end{array}$ & $\begin{array}{c}1.67 \pm 0.58^{\mathrm{b}} \\
(25.00)\end{array}$ & $\begin{array}{c}1.89 \pm 0.38^{\mathrm{b}} \\
(8.33)\end{array}$ & $\begin{array}{c}14.67 \pm 2.52^{\mathrm{b}} \\
(-63.78)\end{array}$ & $\begin{array}{c}15.00 \pm 1.00^{\mathrm{b}} \\
(-66.17)\end{array}$ & $\begin{array}{c}14.67 \pm 1.53^{b} \\
(-60.30)\end{array}$ & $\begin{array}{c}14.78 \pm 1.68^{b} \\
(-63.42)\end{array}$ \\
\hline Susceptible & $\begin{array}{c}4.67 \pm 0.58^{b} \\
(0)\end{array}$ & $\begin{array}{c}4.67 \pm 0.58^{c} \\
(0)\end{array}$ & $\begin{array}{c}5.67 \pm 0.58^{c} \\
(0)\end{array}$ & $\begin{array}{c}5.00 \pm 0.58^{b} \\
(0)\end{array}$ & $\begin{array}{c}2.33 \pm 0.58^{\mathrm{a}} \\
(0)\end{array}$ & $\begin{array}{c}1.67 \pm 0.58^{b} \\
(0)\end{array}$ & $\begin{array}{c}1.33 \pm 0.58^{c} \\
(0)\end{array}$ & $\begin{array}{c}1.78 \pm 0.51^{\mathrm{b}} \\
(0)\end{array}$ & $\begin{array}{c}23.00 \pm 2.00^{c} \\
(0)\end{array}$ & $\begin{array}{c}22.67 \pm 1.53^{c} \\
(0)\end{array}$ & $\begin{array}{c}24.33 \pm 3.06^{c} \\
(0)\end{array}$ & $\begin{array}{c}23.33 \pm 2.20^{c} \\
(0)\end{array}$ \\
\hline
\end{tabular}

Mean values having the same letter superscript along the same column are not significantly different ( $\mathrm{P}=0.05$; Tukey's HSD Test), \% FC = Fitness Cost 
There was an $-25 \%$ increase in the developmental duration or cost in the third duration due to moderate resistance development in the moderate resistant Pipeline population of An. gambiae s.l. when compared to the susceptible Airport population. (Table 3). The mean adult developmental longevity in the resistant Oke-odo population in the first generations of survival was $10.67 \pm 2.52$ days. This developmental duration was significantly lower $(\mathrm{P}<0.05)$ than those of the moderately resistant Pipeline population $(14.67 \pm 2.52$ days) and the susceptible Airport population (23.00 \pm 2.00 days). Also, in the moderately resistant Pipeline population in the second and third generation of survival were $15.00 \pm 1.00$ days, $14.67 \pm 1.53$ days, respectively. This developmental duration was significantly lower $(\mathrm{P}<0.05)$ than those of the susceptible Airport population $\left(\mathrm{F}_{2}=22.67 \pm 1.53\right.$ and $\mathrm{F}_{3}=24.33 \pm 3.06$ days). There was a $46.39 \%$ increase in the developmental duration or cost due to full resistance development in the resistant Oke-odo population of An. gambiae s.l. in the first generation, when compared to the susceptible Airport population. Also, it costed the moderately resistant Pipeline population of An. gambiae s.1. 63.78\%, 66.17\% and $60.30 \%$ of its adult developmental duration in the first, second and third generations, respectively when compared to the susceptible Airport population (Table 3).

\subsection{Emergence rate}

Table 4 shows the adult emergence rate and sex ratio of An. gambiae s.l. mosquito samples from three different populations with varying permethrin resistance status in Ilorin, Kwara state. The resistant Oke-odo population at the first generation had a relatively lower emergence of $2.67 \pm 0.58$ adult mosquito which was significantly lower $(\mathrm{P}<0.05)$ than emergence rate from moderately Resistant Pipeline (32.33 \pm 5.69$)$ and susceptible Airport $(115.67 \pm 11.68)$ populations. Meanwhile, in F2 and F3 the adult mosquito emergence in Pipeline populations $\left(\mathrm{F}_{2}=39.67 \pm 8.33\right.$ and $\left.\mathrm{F}_{3}=20.33 \pm 2.08\right)$ were significantly lower $(\mathrm{P}<0.05)$ than the adult mosquito emergence from the Airport population $\left(\mathrm{F}_{1}\right.$ $=115.67 \pm 11.68, \quad F_{2}=72.33 \pm 11.02$ and $F_{3}=$ $54.67 \pm 3.21$ ). In the susceptible population, there was a steady decrease in adult mosquito emergence across generations. There was a $97.69 \%$ decrease in the adult mosquito emergence rate or cost due to full resistance development in the resistant Oke-odo population of An. gambiae s.l. in the first generation, when compared to the susceptible Airport population. Also, it costed the moderately resistant Pipeline population of An. gambiae s.1. $72.05 \%$, $45.15 \%$ and $62.81 \%$ of its adult emergence in the first, second and third generations, respectively when compared to the susceptible Airport population (Table 4).

\subsection{Sex ratio}

In the resistant Oke-odo population, the ratio of male adult mosquitoes was higher than that of the females (1:0.6) in the first generation but there was no significant difference $(\mathrm{P}>0.05)$ between them. Meanwhile, in the moderately resistant Pipeline population, in the first generation the ratio of female adult mosquitoes was higher $(\mathrm{P}<0.05)$ than males $(1: 2.7)$ while in the second and third generation the ratio of male adult mosquitoes was higher $(\mathrm{P}<0.05)$ than females $\left(F_{2}=1: 0.6\right.$ and $\left.F_{3}=1: 0.5\right)$. However, in the Susceptible Airport population, the ratio of female adult mosquitoes was higher $(\mathrm{P}<0.05)$ than males in all of the generations observed $\left(F_{1}=1: 1.2\right.$, $\mathrm{F}_{2}=1: 1.2$ and $\mathrm{F}_{3}=1: 1.4$ ) (Table 4).

\subsection{Biological Fitness Cost}

Table 5 shows the biological fitness costs associated with varying permethrin resistance status in $A n$. gambiae s.l. from three different populations from Ilorin, Kwara State. The average fecundity rate showed that the susceptible population from Airport laid $87.89 \pm 31.58$ average number of eggs which was significantly higher $(\mathrm{P}<0.05)$ than those of the moderately resistant $(31.81 \pm 8.62)$ and full resistant $(9.89 \pm 8.83)$ populations. There was a $90.21 \%$ fecundity cost due to full resistance development in the resistant Oke-odo population of An. gambiae s.l. when compared to the susceptible population from Airport. Also, it costed the moderately resistant population of An. gambiae s.l. from Pipeline $61.71 \%$ fecundity cost when compared to the susceptible population from Airport (Table 5). The average hatchability rate showed that the susceptible population from Airport hatched 83.67 \pm 31.39 average number of eggs which was significantly higher $(\mathrm{P}<0.05)$ than those of the moderately resistant $(38.56 \pm 13.67)$ and full resistant (3.44 \pm 3.20$)$ populations. There was a $96.20 \%$ hatchability cost due to full resistance development in the resistant Oke-odo population of An. gambiae s.l. when compared to the susceptible population from Airport. Also, it costed the moderately resistant population of An. gambiae s.l. from Pipeline 52.00\% hatchability cost when compared to the susceptible population from Airport (Table 5). 
Table 4. The adult emergence rate and sex ratio of An. gambiae s.l. mosquito samples from three different communities in Ilorin, Kwara state.

Mean values having the same letter superscript along the same column are not significantly different ( $\mathrm{P}=0.05$; Tukey's HSD Test), \% FC = Fitness Cost, R = Ratio

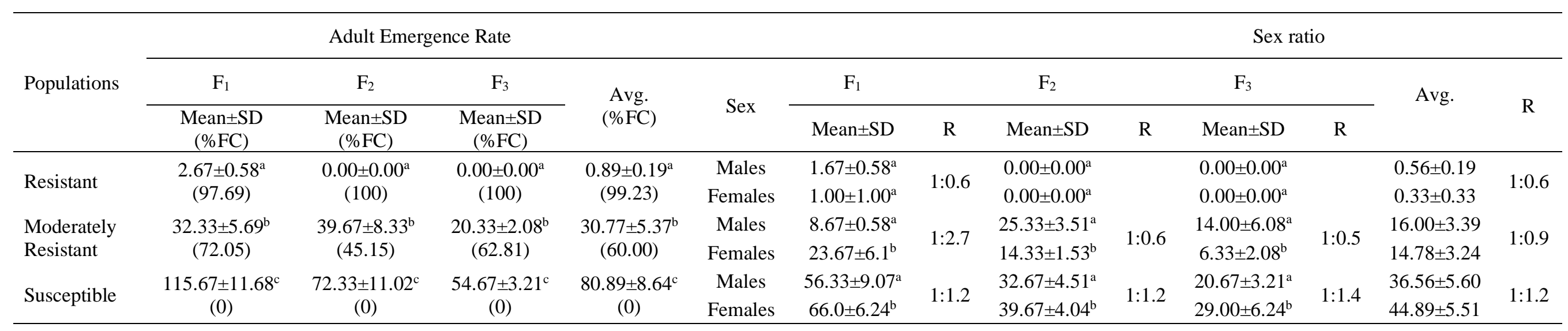

Table 5. Biological Fitness cost associated with Permethrin resistance status variation in An. gambiae s.l. from Ilorin, Nigeria.

\begin{tabular}{ccccc}
\hline Biological feature & $\begin{array}{c}\text { The actual value } \\
\text { recorded in the } \\
\text { susceptible } \\
\text { population }\end{array}$ & $\begin{array}{c}\text { Permethrin } \\
\text { Susceptible }\end{array}$ & $\begin{array}{c}\text { Permethrin } \\
\text { Moderately } \\
\text { Resistant }\end{array}$ & Permethrin Resistant \\
\cline { 3 - 5 } & $87.89 \pm 31.58$ & 0.00 & +61.71 & +90.21 \\
Fecundity Rate & $83.67 \pm 31.39$ & 0.00 & +52.00 & +96.20 \\
Hatchability Rate & $5.00 \pm 0.58$ & 0.00 & -18.91 & -59.52 \\
Larvae Longevity & $1.78 \pm 0.51$ & 0.00 & 8.33 & -66.67 \\
Pupae Longevity & $23.33 \pm 2.20$ & 0.00 & -63.42 & -82.13 \\
Adult Longevity & $80.89 \pm 8.64$ & 0.00 & 60.00 & 99.23 \\
Adult emergence rate & & & &
\end{tabular}


The average longevity rate showed that in the resistant population from Oke-odo, the larvae (4.33 \pm 3.76 days), pupae $(0.78 \pm 1.35$ days $)$ and adult (3.56 \pm 0.84 days) stages of An. gambiae s.l. spent significantly shorter $(\mathrm{P}<0.05)$ developmental duration when compared with the moderately resistant $($ Larvae $=6.00 \pm 1.53$ days, Pupae $=$ $1.89 \pm 0.38$ days and Adult $=14.78 \pm 1.68$ days $)$ and susceptible $($ Larvae $=5.00 \pm 0.58$ days, Pupae $=$ $1.78 \pm 0.51$ days and Adult $=23.33 \pm 2.20$ days) populations. There was a $58.52 \%, 66.67 \%$ and $82.13 \%$ longevity cost due to full resistance development in the resistant Oke-odo population of An. gambiae s.l. larvae, pupae and adult respectively, when compared to the susceptible population from Airport. Also, it costed the moderately resistant population of An. gambiae s.l. from Pipeline $18.91 \%,-8.33 \%$ and $63.42 \%$ longevity cost in the larvae, pupae and adult stages respectively when compared to the susceptible population from Airport (Table 5). The average adult emergence rate showed that the susceptible population from Airport had 80.89 \pm 8.64 adult mosquitoes emerge which was significantly higher $(\mathrm{P}<0.05)$ than those of the moderately resistant $(30.77 \pm 5.37)$ and full resistant $(0.89 \pm 0.19)$ populations. There was a $99.23 \%$ adult emergence cost due to full resistance development in the resistant Oke-odo population of An. gambiae s.l. when compared to the susceptible population from Airport. Also, it costed the moderately resistant population of An. gambiae s.1. from Pipeline $60.00 \%$ adult emergence cost when compared to the susceptible population from Airport (Table 5).

\section{Discussion}

This study was able to establish three Permethrin resistance statuses in An. gambiae s.l. from three different communities in Ilorin, Kwara State, Nigeria. This agrees with Awolola et al. (2018) and Balarabe et al. (2015) that opined that populations of the same mosquito species exist at various resistance status depending on anthropogenic activities and mosquito management strategies. Earlier works (unpublished data) by the same group of researchers had shown that and given an incline that was subsequently confirmed, made it seem less problematic getting the Airport population for use as a control group for this research.

The egg-laying capability was significantly reduced in the resistant and moderately resistant population of An. gambiae s.l. indicating a colossal fitness cost. The study noted a fecundity cost as high as $86.70 \%$ in resistant and $71.83 \%$ in moderately resistant $A n$. gambiae s.l. and this improves with generations. The resistant populations were, in fact, unable to lay eggs (no fecundity) by the third generation. This observation conforms with those reported in deltamethrin resistant An. labrachiae by Tabbabi \& Daaboub (2018) where there was a fecundity disadvantage when compared with the susceptibility counterpart. Also, this trend was confirmed by Thiago et al. (2012) in organophosphate resistant Aedes aegypti and Olorunfemi et al. (2016) in cypermethrin resistant Culex quinquefasciatus. These studies, however, did not consider the generational effect which this study considered. The knowledge accrued from this study will go a long way to help mosquito managers to see that full and moderate permethrin resistance has a significant effect on the fecundity of An. gambiae s.l. a major vector of malaria, changing the negative narrative around resistance development in Africa.

Permethrin resistance in An. gambiae s.l. also had a cost with respect to egg hatchability. The rate of hatching in resistant An. gambiae s.l. populations were significantly reduced showing that permethrin resistance poses a terminal hatchability disadvantage to An. gambiae s.l. which may be desirable to mosquito managers. This finding is similar to reports by Thiago et al. (2012) where hatchability disadvantage was recorded in Temphos resistant Aedes aegypti when compared with its susceptible counterpart. Also, Olorunfemi et al. (2016) reported that cypermethrin resistance had significantly reduced the hatchability of eggs laid by deltamethrin resistant strain of Culex quinquefasciatus. Fecundity and hatchability disadvantage in the insecticide-resistant population can be exploited for Anopheles vector management since their population and vector competence is dependent on their fecundity and hatchability.

Several life history parameters were affected by permethrin resistance development in this research work, and one of them is the developmental duration of the different life stages of An. gambiae s.l. The time it takes to complete larval development is of particular interest, since the longer it takes to develop, the higher the exposure risk to adverse conditions and natural predators and pathogens in their natural breeding habitat (Thiago \& Ademir, 2016). The study established a significant increase in the larval stage of developmental time with permethrin resistant development. Permethrin resistant population of $A n$. gambiae s.l. when compared to the susceptible population had $59.52 \%$ improvement in larval duration. This is in contradiction to studies by Tabbabi \& Daaboub (2018) where he reported that the larval stage of deltamethrin resistant An. labrachiae population spent more time developing when compared to the susceptible counterpart. The results from this study are important in Anopheles vector management 
because the shorter it takes for the larval stage to develop, the more difficult it is to deploy biological strategies like the use of natural predators and pathogens to manage them. The knowledge from this study, therefore, opens up opportunities for mosquito managers to be able to implement management strategies that focus on the larval stage in their natural breeding sites. Also, the study was able to establish that the number of adults $A n$. gambiae s.l. that emerged from the permethrin resistant population in the first generation was significantly less when compared with the susceptible population. Also, worthy to note is that no adult mosquitoes emerged in the second and third generation of the full resistant population. The goal of all vector control activities is to reduce the number of the mosquito population hence reducing disease transmission. The information from this study will influence decisions with regards to how to manage permethrin resistance development in $A n$. gambiae s.l. since the study shows that it affects their adult emergence rate generation wise.

There was also a significant decrease in adult longevity with permethrin resistant development when compared with the susceptible population Adults of An. gambiae s.l. have been incriminated in disease transmission because, in the process of sourcing for a blood meal which is necessary for the development of their progeny, they transmit diseasecausing pathogens and parasites hence human perspective. Recently, there has also been an upscale of permethrin resistance development in $A n$. gambiae s.l. in Nigeria (Awolola et al., 2007, Balarabe et al., 2015, Okorie et al., 2015, Habibu et al., 2017, Nwankwo et al., 2017, Awolola et al., 2018 and Oduola et al., 2019). The study, therefore, shows that the present permethrin resistance status of An. gambiae s.l. in Nigeria shortens the adult life span hence limiting its vectorial capacity which is very beneficial to man.

The study was able to establish that permethrin resistant development in An. gambiae s.l. the population would affect the sex ratio with the emergence of significantly more adult male mosquitoes in proportion to the females, as compared to the susceptible population which had more proportion of females in relation to the number of males. This is similar to the findings by Sanil \& Shetty (2012) where they reported that Temphos and Propoxur resistance in Culex pipiens induced a bias in favour of the male sex. This study proves that sexual ratio in resistant population favours the males which can be seen as an advantage to mosquito managers. Adult females An. gambiae s.l. have been incriminated in the transmission of disease-causing parasites and pathogens in their quest for blood meals, therefore, having more males and fewer females in our environment will reduce disease transmission hence indirectly achieving vector control goals.

\section{Conclusion}

Resistance development in insects, though seemingly counterproductive as it negates the expectations of the insecticide user, should not be seen as a major challenge with regards to mortality as it confers great disadvantage to the life history of Permethrin resistant An. gambiae s.l. as established in this study. The study has been able to establish that Permethrin resistance development in $A n$. gambiae s.l. is a disadvantage to the organism in terms of fecundity, hatchability and developmental time of different life stages as well as sex ratio over so many generations. Hence, permethrin resistant disadvantage in adult An. gambiae s.l. should not be seen as an issue anymore but has an advantage that can be leveraged upon in Anopheles vector management.

\section{Acknowledgement}

Gratitude goes to the Entomological Laboratory of the Department of Zoology, University of Ilorin for space and study atmosphere.

\section{References}

Awolola, T.S., Adeogun, A., Olakiigbe, A.K., Oyeniyi, T., Olukosi, Y.A., Okoh, H. (2018) Pyrethroids resistance intensity and resistance mechanisms in Anopheles gambiae from malaria vector surveillance sites in Nigeria, PLOS ONE 13 (12): e0205230.

Awolola, T.S., Oduola, A.O, Oyewole, I.O., Obansaa, J.B., Amajoh, C.N., Koekemoer, L.L. Coetzee, M. (2007) Dynamics of knockdown pyrethroid insecticide resistance alleles in a field population of Anopheles gambiae s.s. in southwestern Nigeria, Journal of Vector Borne Diseases 44: 181-188.

Balarabe, R.M., Yayo, M.A., Yusuf, Y.D. (2015) Insecticide resistance of Anopheles spp. mosquitoes (Diptera: Culicidae) in Nigeria, International Journal of Mosquito Research 2(3): 56-63.

Brown, Z.S., Dickinson, K.L., Kramer, R.A. (2013) Insecticide resistance and malaria vector control: the importance of fitness cost mechanisms in determining economically optimal control trajectories, Journal of Economical Entomology 106: 366-374.

Gillies, M. T., Coetzee, M. A. (1987) Supplement to the Anophelinae of Africa, South of the Sahara (Afrotropical region), Publications of the South 
African Institute of Medical Research 55: 141 143.

Habibu, U.A., Andrew, J.S., Hapca, S., Mukhtar, M.D., Yusuf Y.D. (2017) Malaria Vectors Resistance to Commonly Used Insecticides in the Control of Malaria in Bichi, Northern Nigeria, Bayero Journal of Pure and Applied Sciences 10(1): 1 - 6, ISSN 2006 - 6996.

Jaramillo, O.N., Fonseca-Gonzalez, I., ChaverraRodríguez, D. (2014) Geometric morphometrics of nine field isolates of Aedes aegypti with different resistance levels to lambda-cyhalothrin and relative fitness of one artificially selected for resistance, PLOS ONE 9: e96379

Lyons, C., Oliver, S., Hunt, R., Coetzee, M. (2016) The influence of insecticide resistance, age sex, and blood feeding frequency on thermal tolerance of wild and laboratory phenotypes of Anopheles funestus (Diptera: Culicidae), Journal of Medical Entomology 53: 394-400.

Nwankwo, E.N., Okorie, P.N., Acha, C.T., Okonkwo, O.E., Nwangwu, U.C., Ebuka, K. (2017) Insecticide Resistance in Anopheles gambiae s.l. Mosquitoes in Awka, Anambra State, Southeast Nigeria, Journal of Mosquito Research 7(5) doi: 10.5376/jmr.2017.07.0005

Oduola, A.O., Abba, E., Adelaja, O.J., Ande, A.T., Yoriyo, K.P., Awolola, T.S. (2019) Widespread Report of Multiple Resistance in Anopheles gambiae Mosquitoes in Eight Communities in Southern Gombe, North East Nigeria, Journal of Arthropod Borne Diseases.

Okorie, P.N., Ademowo, G.O., Irving, H., KellyHope, L.A., Wondji, C. S. (2015) Insecticide susceptibility of Anopheles coluzzii and Anopheles gambiae mosquitoes in Ibadan, South-West Nigeria, Medical and Veterinary Entomology 29(1): doi:10.1111/mve.12089.

Okoye, P., Brooke, B., Hunt, R., Coetzee, M. (2007) Relative developmental and reproductive fitness associated with pyrethroid resistance in the major southern African malaria vector Anopheles funestus, Bulletin of Entomology Research 97: 599-605.

Olayemi, I.K., Ande, A.T. (2009) Life table analysis of Anopheles gambiae (Diptera: Culicidae) in relation to malaria transmission, Journal of Vector Borne Diseases 46: 295-298.

Olorunfemi, O.S., Akinwande, K.L. and Ashamo, M.O. (2016) Laboratory review of sublethal effects of cypermethrin on oviposition, life span and egg development in Culex quinquefasciatus, Say (Diptera: Culicidae), International Journal of Mosquito Research 3(6): 20-25.
Rahim, J., Ahmed, A.H., Maimus A.H. (2017) Effects of temephos resistance on life history traits of Aedes albopictus, Revista Brasileira de Entomologia 61: 312 -317.

Rivero, A., Magaud, A., Nicot, A. and Vezilier, J. (2011) Energetic cost of insecticide resistance in Culex pipiens mosquitoes, Journal of Medical Entomology 48:694-700.

Sanil, D., Shetty, N.J. (2012) The effect of sublethal exposure to temephos and propoxur on reproductive fitness and its influence on circadian rhythms of pupation and adult emergence in Anopheles stephensi Liston-a malaria vector, Parasitology Resistance 111: 423-432.

Tabbabi, A., Daaboub, J. (2018) Fitness cost in field Anopheles labranchiae associated with resistance to the insecticide deltamethrin, Revista Brasileira de Entomologia 62: 107-111.

Tabbabi, A., Ben Cheikh, H. (2017) Fitness Cost in Laboratory Selected Strain of the Potential Mosquito Vector of West Nile Virus (Culex pipiens) Associated with Resistance to the Insecticide Temphos, The Journal of Middle East and North Africa Sciences 3(5): 10-15.

The World Gazetteer- Ilorin, Nigeria. (2007) https://www.worldcat.org/title/gazetteer-ofilorin-province/oclc/16501090. Retrieved on 09th February, 2013.

Thiago, A.B., Ademir, J.M. (2016) Insecticide Resistance and Fitness Cost, Intech Open. doi: http://dx.doi.org/10.5772/61826.

Thiago A. B., Martins A., Denise V. (2012) Fitness evaluation of two Brazilian Aedes aegypti field populations with distinct levels of resistance to the organophosphate Temphos, Memoir Institute Oswaldo Cruz 107(7): 916-922.

World Health Organisation (WHO) (2016) Test procedures for insecticide resistance monitoring in malaria vector mosquitoes, 2nd ed. Geneva: Switzerland.

World Health Organisation (WHO) (2019) World malaria report 2019, Geneva. 